\title{
Dry sliding wear behaviour of AA 6061-MWCNT nanocomposites prepared by mechanical alloying
}

\author{
D. Jeyasimman ${ }^{1 *}$, K.Gurunathan ${ }^{2}$, R.Narayanasamy ${ }^{3}$ \\ ${ }^{1,2}$ Department of Mechanical Engineering, Periyar Maniammai University, Thanjavur-613403, Tamil Nadu, \\ India \\ ${ }^{3}$ Department of Production Engineering, National Institute of Technology, Tiruchirappalli-620015, Tamil Nadu, \\ India.
}

\begin{abstract}
In this present investigation, dry sliding wear behavior of AA 6061 nanocrystalline and AA 6061-2 weight percentages (2 wt. \%) of multi-walled carbon nanotubes (MWCNTs) nanocomposites prepared by $30 \mathrm{~h}$ of mechanical alloying (MA) was investigated. Dry sliding wear behavior of prepared nanocomposites at room temperature was estimated by a pin-on-disc wear testing apparatus. Oil hardened non shrinking (OHNS) steel disc was used as the counter face material. Wear tests were conducted for normal loads of 5, 7 and $10 \mathrm{~N}$ at various sliding speed such as 0.6, 0.9, $1.2 \mathrm{~m} / \mathrm{s}$ with the varying sliding distances $(500 \mathrm{~m}, 1000 \mathrm{~m}$ and $1600 \mathrm{~m})$. It was found that, MWCNTs reinforced AA 6061 nanocomposites have low wear rate and less coefficient of friction compared to AA 6061 nanocrystalline. The worn surface morphologies were analyzed by using scanning electron microscopy (SEM). At lower loads, abrasion was the dominant wear mechanism and at higher loads oxidation was the dominant wear mechanism. The formation of oxide layer on the worn surface was examined by energy dispersive spectroscopy (EDS). The results indicated that the addition of MWCNTs as a reinforcement increases the wear resistance of AA 6061 matrix.
\end{abstract}

Keywords: Friction coefficient; Nanocomposite; Wear behaviour; Worn surface morphology

\section{Introduction}

Recently, carbon nanotubes (CNTs) have attracted more attention as an ideal reinforcing material in fabricating composites for their good electrical and thermal properties, extraordinary strength as well as their high elastic modulus values [1-2] after discovered by Iijima [3]. Al-MWCNTs composites could be suitable for the automotive or aerospace industries, where the decrease of fuel consumption by weight reduction and its higher strength are main priorities [4]. Many methods have been explored to incorporate the MWCNTs in to the aluminum matrix in previous researches including high energy ball milling [5-7], spark plasma sintering [8-9], semi-solid powder processing [10-11], friction stir processing [12-13], plasma spraying [14-15] and nanoscale dispersion [16]. However in all these methods, uniform dispersion of MWCNTs is a great challenge due to their high aspect ratio and their strong vander Waals force [17-18]. Among these methods, mechanical alloying (MA) is a solid-state powder processing technique involving repeated welding, fracturing, and rewelding of powder particles in a high-energy ball mill [19]. It was found that the dispersion of reinforcement in aluminum matrix using mechanical alloying depends on various processing variables such as milling time, milling speed, ball-to-powder ratio, type of mill and process control agent [19]. One of the main advantages of MA is the uniform dispersion of reinforcement in metal matrix. However, the MWCNTs would be severely damaged during the later stage of milling [20]. In this present investigation, MWCNTs were added at the last $2 \mathrm{~h}$ of MA (at the end of $28^{\text {th }} \mathrm{h}$ ) to avoid structural damage during milling. Fabrication, consolidation behavior and mechanical properties of MWCNTs reinforced AA 6061 nanocomposites have been investigated already in the previous study [21]. From that study, the structural evolution of MWCNTs before and after milling was investigated by Raman spectroscopy. The results revealed that the MWCNTs sustained less structural damage over $2 \mathrm{~h}$ of mechanical milling. However, because of MWCNTs were added during the last $2 \mathrm{~h}$ of milling, higher hardness values $(76 \mathrm{HV})$ and higher green compression strength (161 MPa) were obtained for AA 6061-2 wt.\% MWCNT nanocomposites [21]. The effect of TiC, alumina and hybrid $\left(\mathrm{TiC}+\mathrm{Al}_{2} \mathrm{O}_{3}\right)$ nanolevel ceramic reinforcements on the dry sliding wear behaviour of the AA 6061 nanocomposites was also investigated in the previous study [22]. So far only a few reports have dealt with dry sliding wear behavior of MWCNTs reinforced aluminum alloy nanocomposite. Choi et al. [23] investigated wear characteristics of Al/MWCNTs composites prepared by ball milling and hot rolling. They reported that $4.5 \mathrm{Vol} . \%$ MWCNTs addition enhanced wear resistance and decreased coefficient of friction. Al-Qutub et al. [24] investigated wear and friction behavior of $\mathrm{Al}$ 6061/MWCNTs nanocomposites for constant sliding speed $(0.5 \mathrm{~m} / \mathrm{s})$ and constant sliding distance $(500 \mathrm{~m})$ prepared by ball milling and spark plasma sintering. They reported that under mild wear conditions, 1 wt. \% MWCNTs reinforced Al6061 composite displayed lower wear rate and friction coefficient compared to the Al6061 monolithic alloy. In one of the recent studies [25], hardness and wear resistance was found to increase 
significantly with CNT content. The wear rate of $5 \mathrm{wt}$ \% CNT composite decreased by $79 \%$ compared to pure aluminium. They observed that CNTs were partially or fully crushed forming a carbon film and acted as a solid lubricant enhancing the wear behaviour significantly. However no detailed investigations have been conducted to the study on effect of MWCNTs on AA 6061 nanocomposites as compared with monolithic AA 6061 alloy for varying sliding speeds and sliding distances.

In this present research work aims to study and investigate the effect of normal loads, sliding velocity and sliding distance on dry sliding wear behavior of AA 6061 nanocomposites with and without MWCNTs reinforcement prepared by mechanical alloying (MA).

The introduction of the paper should explain the nature of the problem, previous work, purpose, and the contribution of the paper. The contents of each section may be provided to understand easily about the paper.

\section{Experimental details}

The starting materials used in the experiment were aluminum powder $(99.5 \%$ purity, $40 \mu \mathrm{m}$, Alfa Aesar, USA) and other pure elemental powders, including silicon, iron, copper, manganese, magnesium, chromium, zinc and titanium with an average particle size of less than $45 \mu \mathrm{m}$ (Alfa Aesar, $99 \%$ purity). The chemical composition required for producing the AA 6061 alloy powder was $96.6 \mathrm{Al}-0.68 \mathrm{Si}-0.7 \mathrm{Fe}-0.275 \mathrm{Cu}-$ $0.15 \mathrm{Mn}-1.0 \mathrm{Mg}-0.195 \mathrm{Cr}-0.25 \mathrm{Zn}-0.15 \mathrm{Ti}$ (wt.\%). MWCNTs of $97 \%$ purity having an inner diameter of $20 \mathrm{~nm}$, outer diameter of $40 \mathrm{~nm}$ and length of $50 \mu \mathrm{m}$ (Redex Nano Lab, India) was used as a reinforcement. Toluene supplied by Ranbaxy, India, was used as a process control agent (PCA). Mechanical alloying was performed in a two-station planetary ball mill (model: Insmart Systems, Hyderabad, India) at $280 \mathrm{rpm}$ with ball to powder ratio 10:1. Nine highly hardened $20-\mathrm{mm}$ diameter steel balls each weighing $33.5 \mathrm{~g}$ (totally $301.5 \mathrm{~g}$ ) were sealed with $30 \mathrm{~g}$ of the powder mixture and toluene in a hardened stainless steel vial for fabrication of AA 6061 alloy matrix. In order to avoid the increase of temperature of vials, the milling process was interrupted each 20 minutes for 10 minutes. The PCA reduces excessive cold welding of powder particles and their adhesion to the vial and balls. Nanostructured AA 6061 powder was first synthesized through $30 \mathrm{~h}$ of MA using all elemental powders. Then these milled powders without reinforcement were designated as AA 6061 nanocrystalline powder. For AA 6061-2 wt. \% MWCNTs nanocomposite preparation, the elemental powders required to produce AA 6061 matrix were milled for up to $28 \mathrm{~h}$. Two weight percentages ( 2 wt. \%) of MWCNTs were added at the end of the $28^{\text {th }} \mathrm{h}$ of milling. The constituent powders were milled for up to $30 \mathrm{~h}$. These milled powders were designated as AA 6061-2 wt.\% MWCNT nanocomposite powder. Cylindrical specimens measuring $\phi 10 \mathrm{~mm}$ and $15 \mathrm{~mm}$ in height were mechanically pressed with a compaction pressure of $500 \mathrm{MPa}$ using a double-action compaction die in a hydraulic press (Insmart systems, Hyderabad, India) with a capacity of 40 tons. The green cylindrical specimens were degassed at $350^{\circ} \mathrm{C}$ for $1 \mathrm{~h}$ and then sintered for $2 \mathrm{~h}$ at a temperature of $525^{\circ} \mathrm{C}$ under nitrogen $\left(\mathrm{N}_{2}\right)$ atmosphere.

Wear test were carried out by a pin-on-disc wear test apparatus (Model DUCOM) at room temperature according to ASTM: G99 and normal applied loads of $5 \mathrm{~N}, 7 \mathrm{~N}$ and $10 \mathrm{~N}$. Cylindrical pins having diameter of 10 $\mathrm{mm}$ and length of $15 \mathrm{~mm}$ were used as pins prepared from sintered AA 6061 nanocrystalline and AA 6061-2 wt.\% MWCNTs nanocomposites. The end of pins surface was maintained without any burr and sharp corners since this surface may damage the disc surface while it was sliding. The surface roughness value of pins was measured and maintained as $0.8 \mu \mathrm{m}(\mathrm{Ra})$ to get uniform wear result. Oil hardened non shrinkage (OHNS) steels with a hardness of $60 \mathrm{HRC}$ were selected as the counterpart and its surface roughness also measured and recorded as $0.45 \mu \mathrm{m}$. The pins and counterpart surfaces were smoothened by using 600 grit sizes SiC paper and cleaned with acetone subsequently. Fine polishing was also done after grinding using diamond paste and a mechanical polishing machine as per ASTM: E3. The surface of pins was checked for the perpendicularity and the flatness to seat with counterpart surface. The prepared pin samples were set in slot which was provided in the arm above the rotating disc. The weights of the pins were measured before and after wear tests by using a sensitive electronic balance with an accuracy of $0.1 \mathrm{mg}$. The experiments were conducted under the normal load of $5 \mathrm{~N}, 7 \mathrm{~N}$ and $10 \mathrm{~N}$ at three different sliding velocities namely $0.6 \mathrm{~m} / \mathrm{s}, 0.9 \mathrm{~m} / \mathrm{s}$ and $1.2 \mathrm{~m} / \mathrm{s}$ for sliding distance up to $1600 \mathrm{~m}$. The weight losses were calculated at every interval of sliding distance for different normal loads with respect to various sliding velocities. The friction coefficient was recorded during sliding by means of a XY plotter attached to the arm to which the pin was attached. The volume loss due to the wear test was calculated from the ratio of weight loss and density. The wear rate was calculated as the ratio between the volume loss and the sliding distance. The wear tests were conducted four times for every pin and the obtained data was represented by the average value together with error bars. TESCAN model VEGA 3 LMU scanning electron microscope was used to analyze the worn out surfaces of all pins morphologies after the wear tests. To examine worn surfaces of pins, a JOEL JEM 2100F field emission scanning electron microscope (FESEM) with EDAX facility was also used. 


\section{Results and Discussion \\ 3.1 Effect of sliding distances and sliding velocity on wear rate}

The wear rates for the AA 6061 nanocrystalline and AA 6061-2 wt.\% MWCNT nanocomposites as function of sliding distance for three sliding velocities (0.6, 0.9 and $1.2 \mathrm{~m} / \mathrm{s}$ ) were shown in Figs.1 (a)-(c). From the Fig. 1 (a), the wear rate increased linearly with increasing sliding distance under applied load because of abrasion wear exhibited for low sliding velocity $0.6 \mathrm{~m} / \mathrm{s}$. The presence of abrasive wear in low velocity has been reported by previous studies also [26-27]. However, Wear rates were lower in AA 6061-2 wt.\% MWCNT nanocomposites compared with AA 6061 nanocrystalline (Figs. 1 (a)-(c)) due to reinforcing fibers which act as load-bearing components and protecting the aluminum matrix surface against destructive action of ploughing process during sliding $[3,28]$. Also carbon based materials can form self-lubricating film, thereby preventing direct contact of sliding surfaces and reducing ploughing effect of hard asperities [3,29-30]. From the Fig. 1 (b), the rate of increase of wear rate from 1000 to $1500 \mathrm{~m}$ sliding distance was high at high load $(10 \mathrm{~N})$ compared to low loads $(5 \mathrm{~N}$ and $7 \mathrm{~N})$ for sliding velocity of $0.9 \mathrm{~m} / \mathrm{s}$ for both nanocrystalline and nanocomposites due to oxidation. At high sliding velocity $(1.2 \mathrm{~m} / \mathrm{s})$, the rate of increase of wear rate from 1000 to $1500 \mathrm{~m}$ sliding distance was comparatively low (Fig. 1 (c)) for all normal applied loads for both nanocrystalline and nanocomposites because of severe oxidation. From the Figs. 1 (a)-(c), it can be seen that the higher wear rate was observed at the higher normal load $(10 \mathrm{~N})$ and at high sliding velocity $(1.2 \mathrm{~m} / \mathrm{sec})$ in the cases of AA 6061 nanocrystalline and AA 6061-2 wt.\% MWCNT nanocomposites. At high loads, adhesion was found to be dominant for both nanocrystalline due to excessive sub-surface fracturing and nanocomposites due to delamination $[2,24]$.

\subsection{Effect of applied load on wear rate}

It was noticed that the wear rate increased with increase of applied load due to increased surface damage and increased the amount of material ploughed. However, The rate of increase of wear rate was increased with increasing applied load from $5 \mathrm{~N}$ to $7 \mathrm{~N}$ and then decreased up to $10 \mathrm{~N}$ was shown in Fig. 2. At low loads, abrasion was the dominant wear for both nanocrystalline and nanocomposites. As the load increased, the width of abrasion groves and the sizes of craters enlarged significantly. AA 6061 nanocrystalline fabricated by powder metallurgy have more pores present in it. As porosity increases, the wear rate increases because pores serve as a source of crack nucleation and propagation resulting in excessive sub-surface fracturing $[2,31]$.

\subsection{Effect of normal applied load and sliding distances on the volume loss}

Figs. 3 (a)-(c) shows the variation in volume loss under all loads and all sliding distances for all sliding velocities $(0.6,0.9,1.2 \mathrm{~m} / \mathrm{s})$. It was noticed that volume loss linearly increased with increasing loads and sliding distances for both nanocrystalline and nanocomposites. However, the rate of increase of volume loss from 1000 to $1500 \mathrm{~m}$ sliding distance was high under higher load $(10 \mathrm{~N})$ compared to lower loads $(5 \mathrm{~N}$ and $7 \mathrm{~N}$ ) for sliding velocities of 0.6 and $0.9 \mathrm{~m} / \mathrm{s}$ for both nanocrystalline and nanocomposites due to oxidation. At high sliding velocity $(1.2 \mathrm{~m} / \mathrm{s})$, the volume loss linearly increased with sliding distance under all normal applied loads for both nanocrystalline and nanocomposites because of severe oxidation. From Figs. 3 (a)-(c), it can be seen that the higher volume loss was observed under the higher normal load $(10 \mathrm{~N})$ compared to lower loads at high sliding velocity $(1.2 \mathrm{~m} / \mathrm{sec})$ in the cases of both AA 6061 nanocrystalline and AA 6061-2 wt.\% MWCNT nanocomposites. Volume loss was low for the case of AA 6061-2 wt.\% MWCNT nanocomposites compared with AA 6061 nanocrystalline due to self lubricating behavior.

\subsection{Effect of normal applied load and sliding distances on friction coefficient}

The friction coefficient of both monolithic alloy and nanocomposites for varying sliding speeds under varying applied loads were shown in the Figs. 4 (a)-(c). The decreasing trend of friction coefficient was observed till the $1600 \mathrm{~m}$ sliding distance under all the applied loads and for varying sliding velocities.

However, the nanocomposites have lower coefficient of friction than nanocrystalline. The average friction coefficient for AA 6061 nanocrystalline and AA 6061-2 wt.\% MWCNT nanocomposites were 0.35 and 0.25 respectively. The addition of $2 \mathrm{wt} . \%$ MWCNTs on AA 6061 matrix reduces the coefficient of friction up to 0.1 (Fig. 4 (a)). Also the coefficient of friction fluctuates around the mean level and decreases as the sliding progresses. This trend was observed irrespective of load and velocities. The variation of coefficient of friction may be due to improper contact between pin and disc. Compared to three different sliding velocities namely 0.6 $\mathrm{m} / \mathrm{sec}, 0.9 \mathrm{~m} / \mathrm{sec}$ and $1.2 \mathrm{~m} / \mathrm{sec}$, lower coefficient of friction was recorded at the higher sliding velocity in all loads. The variation in coefficient of friction was observed in association with the wear mechanism. The coefficient of friction was related to the interaction of asperities between the counter surfaces which in micro scale varies with in specific range throughout the test period. This may result in fluctuation on friction coefficient within a narrow range in each of material with sliding distance [32]. Kim et. al [33] reported a friction coefficient as high as 0.6 for $1 \mathrm{wt} . \%$ CNTs containing composites and 0.65 for Al and Al-Qutub et. al 
[24] reported a friction coefficient 0.35 for same applied load of $5 \mathrm{~N}$. However, in this investigation, friction coefficient for AA 6061-2 wt.\% MWCNT nanocomposites was 0.28 only for the same applied load of 5N (Figs. 4 (a)-(c)). This result seems that MWCNTs were crushed partially and had less structural damage because of $2 \mathrm{~h}$ of mechanical milling.

\subsection{Wear of worn surfaces}

Fig. 5 shows the scanning electron microscope (SEM) of worn surfaces of AA 6061 nanocrystalline and AA 6061-2 wt. \% nanocomposites under different applied loads for sliding velocity of $1.2 \mathrm{~m} / \mathrm{s}$. The wear mechanisms under various sliding conditions could be derived through the analysis for phase, morphology and composition of worn surfaces. Wear mechanisms such as abrasion, delamination and oxidation were observed from SEM micrographs of prepared nanocomposites. Abrasion was the dominant mechanism at the load of 5 and $7 \mathrm{~N}$ (Fig. 5 (a) - (d)). Various grooves and scratches parallel to sliding direction were identified as evident for abrasion mechanism. These were formed due to higher degree of penetration by hard counter face asperities. The wear debris was formed for all loads due to adhesive or fatigue and fretting wear based on the delamination theory [34]. At the load of 7 and $10 \mathrm{~N}$, oxidation was the dominant mechanism. An oxide film was formed between pin surfaces and counter face materials and reduced wear rate (Fig. 5 (b), (d)-(f)) significantly. Fig. 6 shows the energy dispersive spectroscopy of worn surface of AA 6061-MWCNTs nanocomposites at $1.2 \mathrm{~m} / \mathrm{s}$ sliding velocity for sliding distance of $1600 \mathrm{~m}$ under $5 \mathrm{~N}$ loads. This micrograph was confirmed the oxidation.

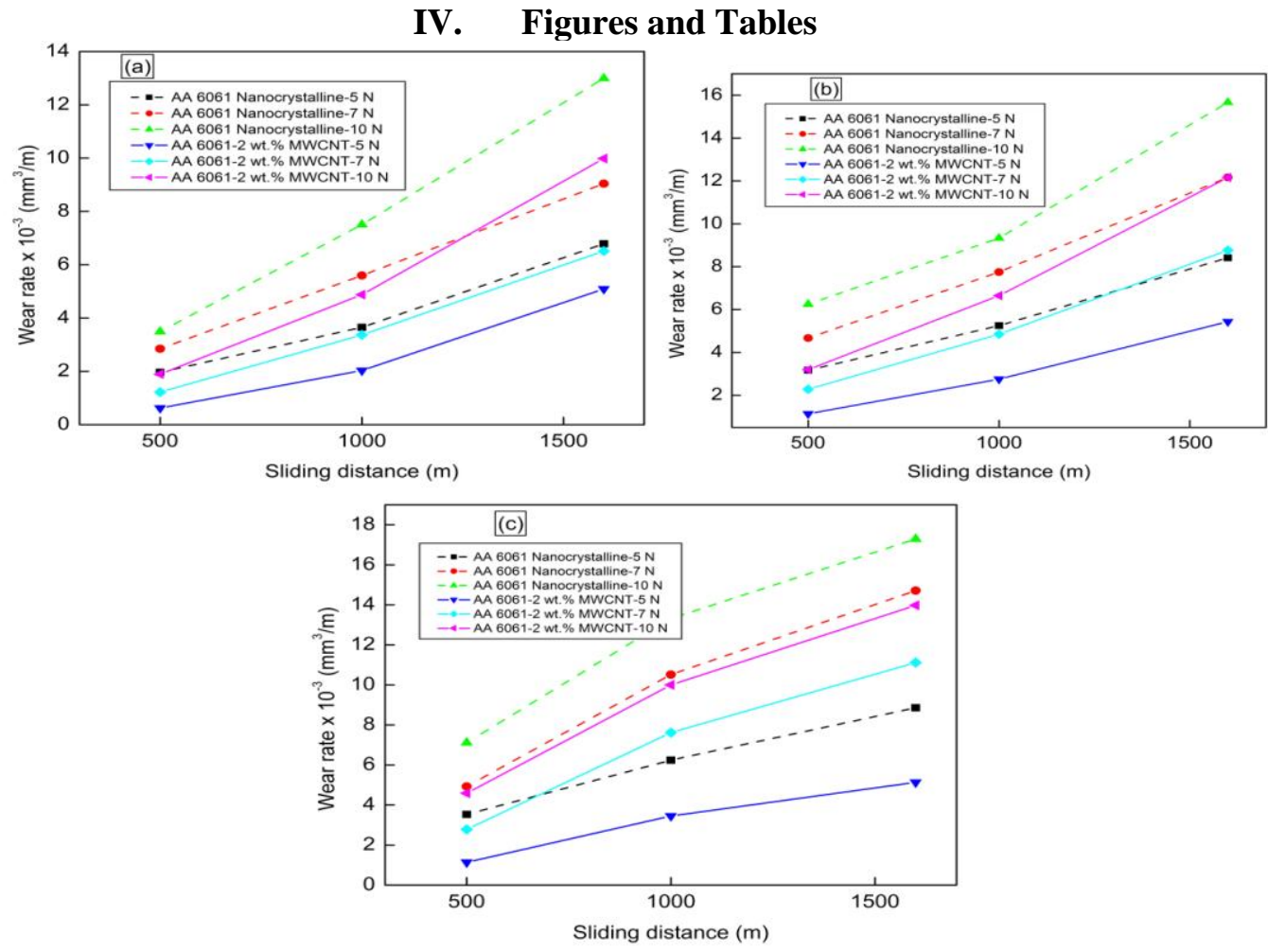

Fig. 1. Variation in wear rate as a function of sliding distance for all applied loads at a sliding velocity of (a) 0.6 $\mathrm{m} / \mathrm{s} ;$ (b) $0.9 \mathrm{~m} / \mathrm{s}$; (c) $1.2 \mathrm{~m} / \mathrm{s}$

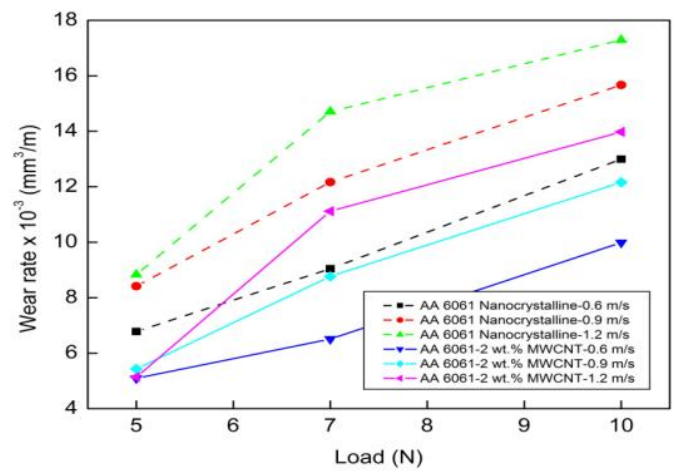

Fig. 2 Variation in wear rate as a function of load for all sliding velocities 

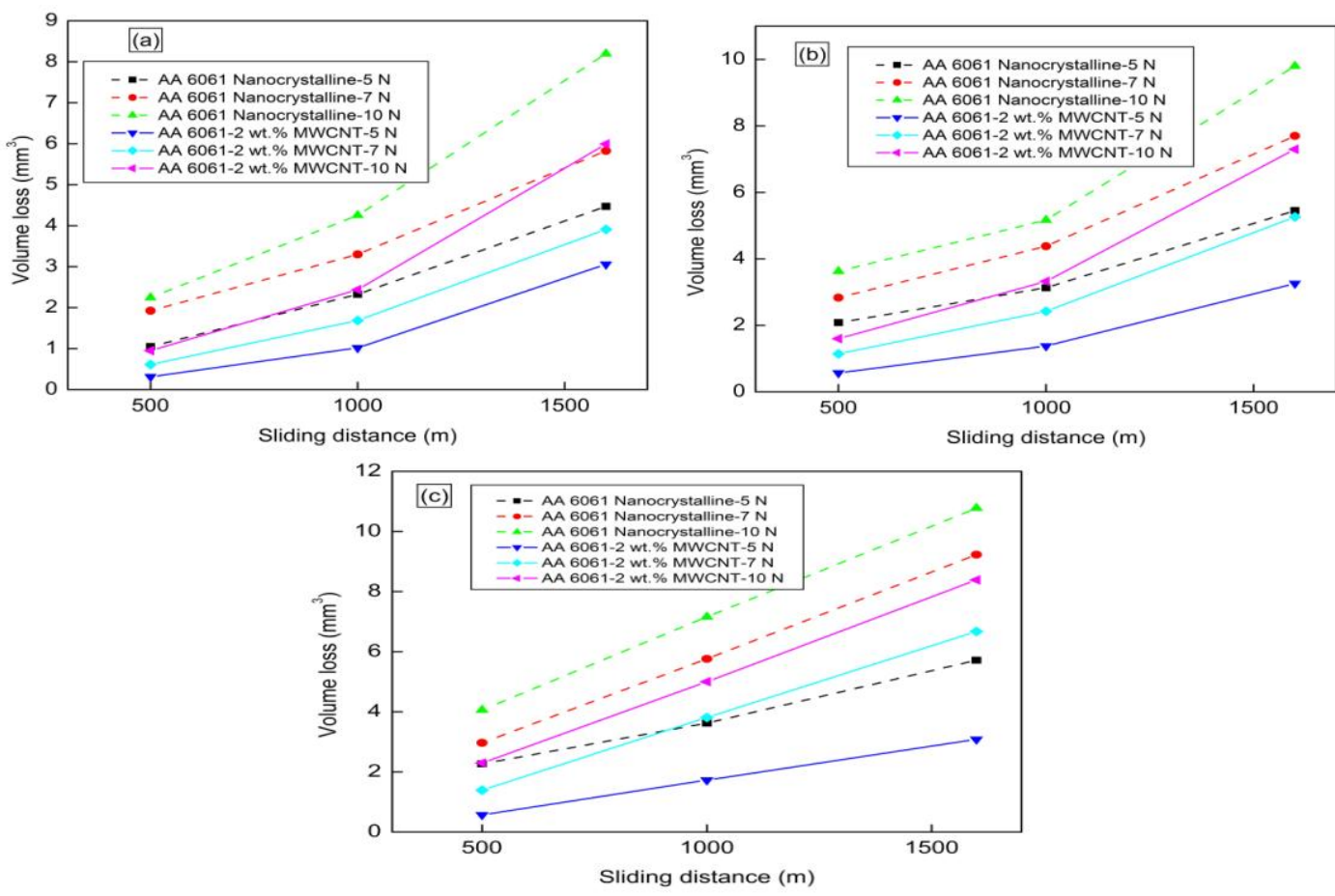

Fig. 3 Variation in volume loss as a function of sliding distance for all normal applied loads at a sliding velocity of (a) $0.6 \mathrm{~m} / \mathrm{s}$; (b) $0.9 \mathrm{~m} / \mathrm{s}$; (c) $1.2 \mathrm{~m} / \mathrm{s}$.
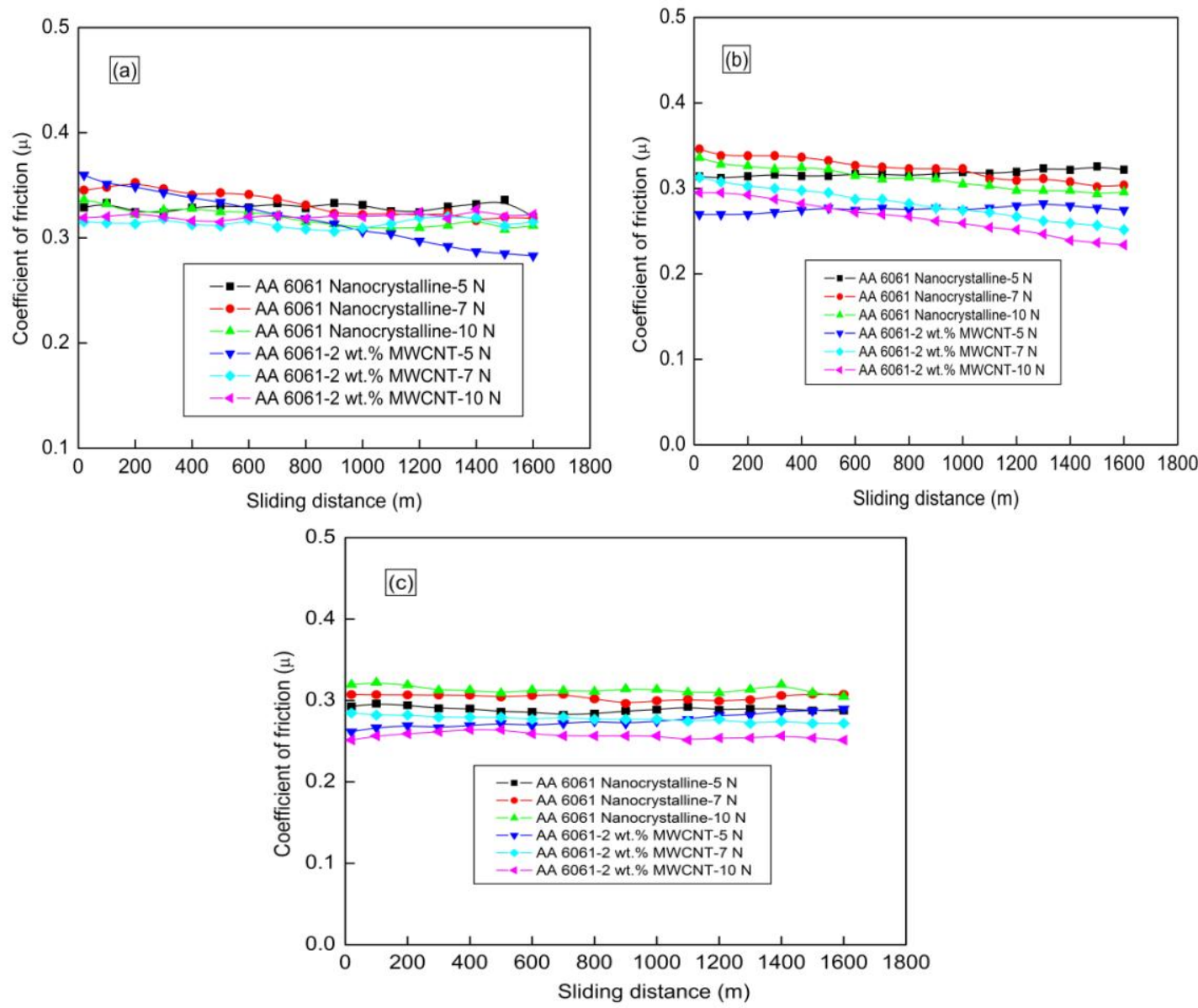

Fig. 4 Variation in coefficient of friction as a function of sliding distance for all normal applied loads at a sliding velocity of (a) $0.6 \mathrm{~m} / \mathrm{s}$; (b) $0.9 \mathrm{~m} / \mathrm{s}$; (c) $1.2 \mathrm{~m} / \mathrm{s}$. 

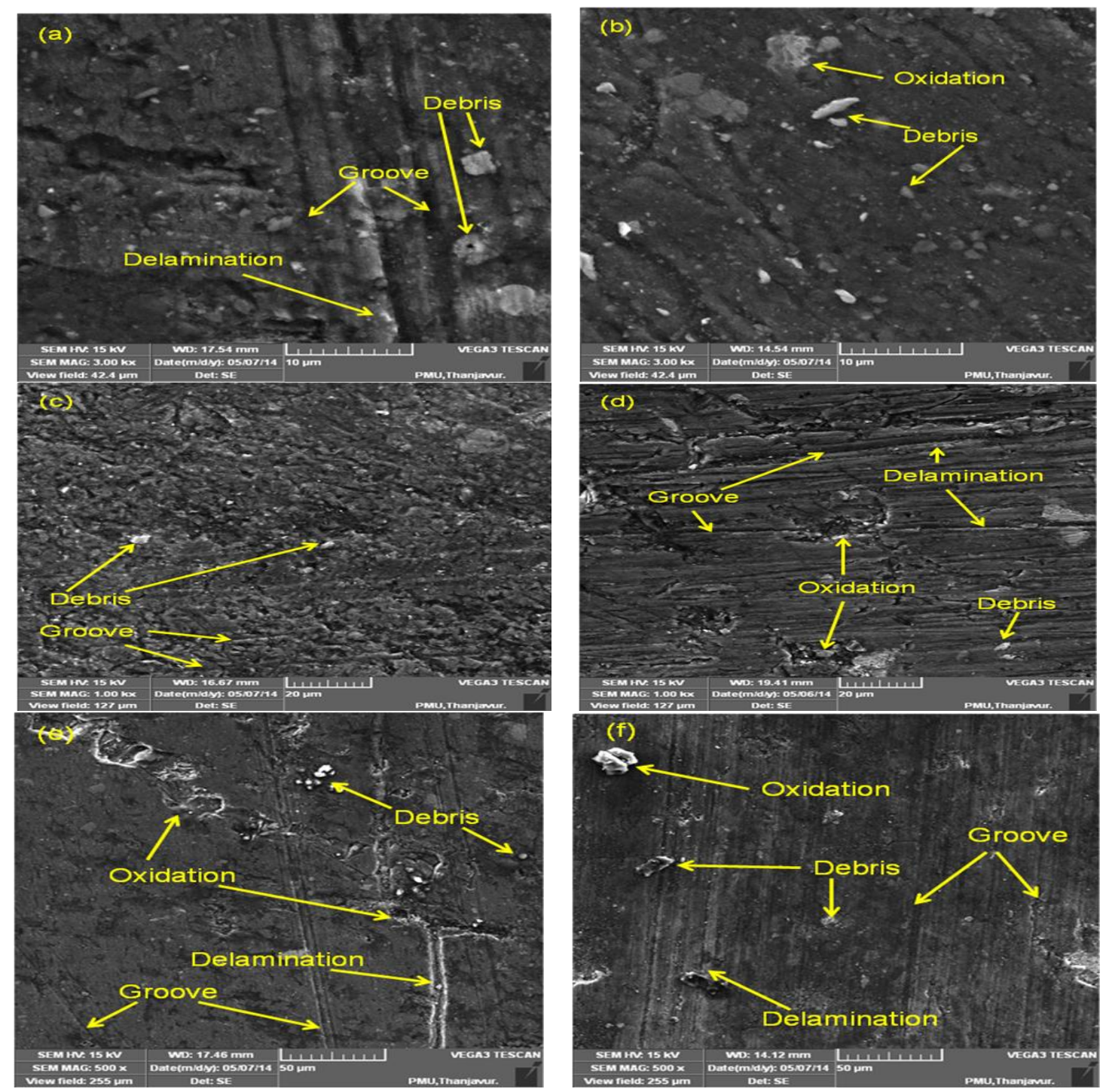

Fig. 5 SEM worn micrographs of AA 6061 nanocrystalline and for (a) $5 \mathrm{~N}$ (c) $7 \mathrm{~N}$ (e) $10 \mathrm{~N}$ and AA 6061-2 wt.\% MWCNT nanocomposites for (b) $5 \mathrm{~N}$ (d) $7 \mathrm{~N}$ and (f) $10 \mathrm{~N}$ at a sliding velocity of $1.2 \mathrm{~m} / \mathrm{s}$.

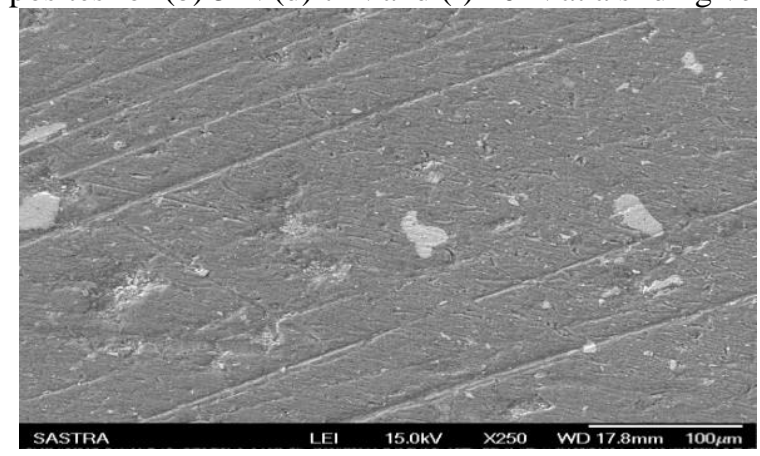




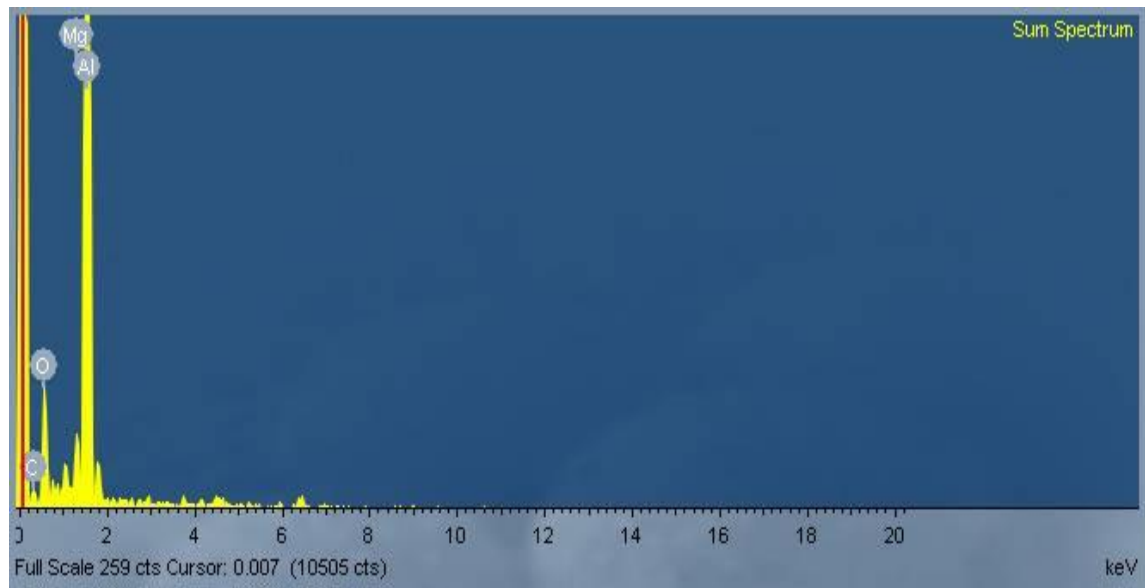

Fig. 6 Energy dispersive spectroscopy (EDS) of worn surface of AA 6061-2 wt.\% MWCNTs nanocomposite at $1.2 \mathrm{~m} / \mathrm{s}$ sliding velocity for sliding distance of $1600 \mathrm{~m}$ under $5 \mathrm{~N}$ load.

\section{Conclusion}

In the present study, dry sliding wear behavior of AA 6061 monolithic alloy and AA 6061-MWCNTs nanocomposites were studied. Effects of applied load, sliding distance and sliding velocity on volume loss and wear rate of prepared nanocomposites were investigated. It was observed that the volume loss and wear rate were lower for AA 6061-MWCNTs nanocomposite compared with monolithic alloy. The addition of MWCNTs in AA 6061 matrix, increased load bearing capacity of AA 6061 nanocomposites samples and consequently increased wear resistance up to 32\%. AA 6061-2 wt.\% MWCNTs nanocomposites had lower friction coefficient compared with AA 6061 monolithic alloy due to self lubricating ability of carbon nanotubes. The various wear mechanisms namely abrasion, delamination and oxidation were established by using scanning electron microscopy. Dominant wear mechanism was identified and the formation of oxide layer were observed and confirmed by using scanning electron microscopy with energy dispersive spectroscopy.

\section{Acknowledgements}

The authors wish to express their gratitude to the General Manager, Heavy Alloy Penetrator Project (HAPP), Tiruchirappalli, Tamil Nadu, India for permitting them to utilize powder metallurgy shop facilities for the preparation of nanocomposites and Dr. M. Kamaraj, Professor \& Head, Indian Institute of Technology, Madras, Tamil Nadu, India for providing wear test facility.

\section{References}

[1]. R.H.Baughman, A.A.Zakhidov, W.A.De Heer. Carbon nanotubes- the route towards application, Science 29, 2002, 787-92

[2]. A.M.K.Esawi, M.M.Farag. Carbon nanotubes reinforced composites: Potential and current challenges, Materials \& Design 28, 2007, 2394-401.

[3]. S.Iijima. Helical microtubules of graphitic carbon, Nature 354, 1991, 56-58

[4]. D.Poirier, R.Gauvin, R.A.L.Drew. Structural characterization of a mechanically milled carbon nanotube/ aluminum mixture, Composites Part A 40, 2009, 1482-89.

[5]. Lin Wang, H.Choi, J.M.Myoung, W.Lee. Mechanical alloying of multi-walled carbon nanotubes and aluminum powders for the preparation of carbon/metal composites, Carbon 47, 2009, 3427-3433.

[6]. R.Perez Bustamante, C.D.Gomez-Esparza, I. Estrada-Guel, M.Miki Yoshida. Microstructural and mechanical characterization of Al-MWCNT composites produced by mechanical alloying, Materials Science and Engineering A 502, 2009, $159-163$.

[7]. A.M.K.Esawi, K.Morsi, A.Syed, M.Taher, S.Lanka. The influence of carbon nanotube (CNT) morphology and diameter on the processing and properties of CNT-reinforced aluminum composites, Composites A 42, 2011, 234-243.

[8]. J.Wu, H.Zhank, Y.Zhank, X.Wang. Mechanical and thermal properties of carbon nanotube/ aluminum composites by spark plasma sintering, Materials \& Design 41, 2012, 344-348.

[9]. J.Z.Liao, M.J.Tan, I.Sridhar. Spark Plasma sintered multi-wall carbon nanotube reinforced aluminum matrix composites, Materials \& Design 31, 2010, S96-S100.

[10]. Yufeng Wu, Gap-Yong Kim. Carbon nanotube reinforced aluminum composite fabricated by semi-solid powder processing, Journal of Materials Processing Technology 211, 2011, 1341-1347.

[11]. Yufeng Wu, Gap-Yong Kim, A.M.Russell. Effects of mechanical alloying on Al 6061-CNT composite fabricated by semi-solid powder processing, Materials Science and Engineering A 538, 2012, 164-172.

[12]. Z.Y.Liu, B.L.Xiao, W.G.Wang, Z.Y.Ma. Singly dispersed carbon nanotube/aluminum composites fabricated by powder metallurgy combined with friction stir processing, Carbon 50, 2012, 1843-1852.

[13]. Z.Y.Liu, B.L.Xiao, W.G.Wang, Z.Y.Ma. Elevated temperature tensile properties and thermal expansion of CNT/2009Al composites, Composites Science and Technology 72 (15), 2012, 1826-33.

[14]. T.Laha, A.Agarwal, Tim Mckechnie, S.Seal. Synthsis and characterization of plasma spray formed carbon nanotube reinforced aluminum composite, Materials Science and Engineering A 381, 2004, 249-58.

[15]. S.R.Bakshi, V.Singh, S.Seal, A.Agarwal. Aluminum composite reinforced with multiwalled carbon nanotubes from plasma spray dried powders, Surface and Coating Technology 203, 2009, 1544-54. 
[16]. T.Noguchi, A.Magario, S.Fukazawa, S.Shimizu, J.Beppu, M.Seki. Carbon nanotubes/Aluminum composites with Uniform Dispersion, Materials Transaction 45 (2), 2004, 602-604.

[17]. J.H.Park, P.S.Alegaonkar, S.Y.Jeon, J.B.Yoo. Carbon nanotube composite: Dispersion routes and field emission parameters, Composites Science and Technology 68 (3-4), 2008, 753-59.

[18]. Kim HS, Park W, Kang M, Jin HJ. Multiple light scattering measurement and stability analysis of aqueous carbon nanotube dispersions, Journal of Physics Chemistry Solids 69, 2008, 1209-12.

[19]. C.Suryanarayana. Mechanical alloying and milling, Progressive in Material Science 46 (1), 2001, 1-184.

[20]. Konya Z, Zhu J, Niesz K, Mehn D, Kiricsi I. End morphology of ball milled carbon nanotubes, Carbon 42, 2004, 2001-8.

[21]. D.Jeyasimman, K.Sivaprasad, S.Sivasankaran, R.Narayanasamy. Fabrication and consolidation behavior of Al 6061 nanocomposite powders reinforced by multi-walled carbon nanotubes, Powder Technology 258, 2014, 189-197.

[22]. D.Jeyasimman, R.Narayanasamy, R.Ponalagusamy, V.Anandakrishnan, M.Kamaraj. The effects of various reinforcements on dry sliding wear behaviour of AA 6061 nanocomposites, Materials \& Design 64, 2014, 783-793.

[23]. H.J.Choi, S.M.Lee, D.H.Bae. Wear Characteristic of aluminum-based composites containing multi-walled carbon nanotubes, Wear 270, 2010, 12-18.

[24]. A.M.Al-Qutub, A.Khalil, N.Saheb, A.S.Hakeem. Wear and friction behavior of Al 6061 alloy reinforced with carbon nanotubes, Wear 297, 2013, 752-761.

[25]. M.M.H.Bastwros, A.M.K.Esawi, A.Wifi. Friction and Wear behavior of Al-CNT composites, Wear 30, $2013,164-73$.

[26]. M.Shanthi, Q.B.Nguyen, M.Gupta. Sliding wear behavior of calcium containing AZ 31 B/Al $\mathrm{O}_{3}$ nanocomposites, Wear 269 (5-6), 2010, 473-79.

[27]. C.Y.H.Lim, D.K.Leo, J.J.S.Ang, M.Gupta. Wear of magnesium composites reinforced with nano-sized alumina particulates, Wear $259,2005,620-25$

[28]. S.C.Tjong. Recent progress in the development and properties of novel metal matrix nanocomposites reinforced with carbon nanotubes and graphene nanosheets, Materials Science and Engineering $R$ 74 (10), 2013, 281-350.

[29]. S.V.Prasad, B.D.Mcconell. Tribology of aluminum metal-matrix composites: lubrication by graphite, Wear 149, 1991, 241-53.

[30]. F.Akhalagi, A.Zare-Bidaki. Influence of graphite content on the dry sliding and oil impregnated sliding wear behavior of Al 2024graphite composites produced by insitu powder metallurgy method, Wear 266, 2009, 37-45.

[31]. S.M.Zhou, X.B.Zhong, Z.P. Ding, C.Y.Min, G.L.Xu. W.M.Zhu. Fabrication and tribolgical properties of carbon nanotubes reinforced Al composites prepared by pressure less infiltration technique, Composites Part A 38, 2007, 301-6.

[32]. A.Mazahery, M.O.Shabani. Study on microstructure and abrasive wear behavior of sintered Al matrix composites. Ceramics Int. 38, 2012, 4263-69.

[33]. I.Y.Kim, J.H.Lee, C.S.Lee, S.H.Baik, Y.J.Kim. Y.Z.Zee. Friction and wear characteristics of carbon nanotubes-aluminum composites with different manufacturing conditions, Wear 267, 2009, 593-98.

[34]. N.P.Suh. An overview of the delamination theory of wear, Wear 44, 1977, 1-16. 